\title{
Posbióticos: a nova era no tratamento da saúde intestinal do atleta?
}

- A microbiota está diretamente implicada em áreas vitais para a saúde do atleta já que influencia sua função imune, sua saúde intestinal e até mesmo a produção energética;

- O exercício tem a capacidade de modular beneficamente a composição da microbiota - mas pode gerar algum grau de alteração intestinal quando for intenso e/ou de longa duração;

- Pensando em recuperar e manter a microbiota do atleta, o nutricionista deverá priorizar em seu plano alimentar a ingestão de fibras e alimentos com prebióticos, fortalecendo assim a microbiota nativa;

- Entretanto, considerando-se as características individuais e os fatores associados ao treino, a suplementação de probióticos pode ser benéfica em alguns casos. Mas essa estratégia só será viável se for acompanhada de uma dieta individualizada em que o profissional remova todos os fatores alimentares que podem influenciar negativamente a permeabilidade da mucosa intestinal e o equilíbrio da microbiota;

- Apesar dos resultados encontrados em alguns estudos, uma revisão de 2017 pontua que ainda falta um consenso sobre a real efetividade da suplementação de probióticos em atletas em função de algumas limitações dos estudos disponíveis, tais como: pequeno número de voluntários avaliados; curto período de suplementação; efeitos dosedependente; ausência de recomendações específicas para atletas e de controle do nível de atividade física dos participantes;

- Os posbióticos correspondem a fração solúvel intracelular secretada por bactérias vivas ou liberada após a lise bacteriana - ou seja, subprodutos metabólicos e/ou componentes da parede celular de probióticos (Lactobacilos e Bifidobactérias) - e, devido a sua bioatividade, podem mimetizar os efeitos benéficos dos probióticos sem a necessidade de administrar micro-organismos vivos, reduzindo assim possíveis efeitos colaterais;

- Além das frações bacterianas, os polifenóis também podem ser considerados posbióticos, já que são extensivamente metabolizados pela microbiota intestinal resultando na produção de diversos metabólitos;

- Assim, trabalhar com posbióticos fornece estratégias personalizadas e integradas que respeitem a fisiologia individual e considerem a variabilidade interindividual dependente da composição específica da microbiota;

- Entretanto, seu uso na prática clínica ainda é limitado. Já há algumas limitações como possíveis interações inesperadas entre microbiota-posbióticos resultando em disbiose ou formação de substâncias potencialmente tóxicas ou inativas; possíveis mecanismos de resistência em função da exposição crônica a tais metabólitos; e estrutura química complexa que pode ser de difícil replicação no ambiente industrial/laboratorial.

\section{Referências bibliográficas}

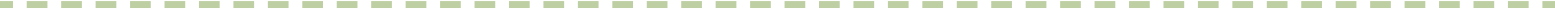
1. COQUEIRO, A.Y.; GARCIA, A.B.O.; ROGERO, M.M.; TIRAPEGUI, J. Probiotic supplementation in sports and physical exercise: Does it present any ergogenic effect? Nutrition and Health; 23(4) 239-249, 2017.

2. CLARK, A.; MACH, N. The Crosstalk between the Gut Microbiota and Mitochondria during Exercise. Front Physiol; 8:319, 2017. doi: 10.3389/ fphys.2017.00319.

3. DIDUCH, B.K. Gastrointestinal Conditions in the Female Athlete. Clin Sports Med; 36: 655-669, 2017.

4. BARTON, W.; PENNEY, N.; CRONIN, O. et al. The microbiome of professional athletes differs from that of more sedentary subjects in composition and particularly at the functional metabolic level. Gut; 67:625-633, 2018.

5. RANKIN, A.; O'DONOVAN, C.; MADIGAN, S.M. et al. 'Microbes in sport' -The potential role of the gut microbiota in athlete health and performance. Br J Sports Med; 51 (9): 698-699, 2017.

6. ROBERTS, J.D.; SUCKLING, C.A.; PEEDLE, G.Y. et al. An Exploratory Investigation of Endotoxin Levels in Novice Long Distance Triathletes, and the Effects of a Multi-Strain Probiotic/Prebiotic, Antioxidant Intervention. Nutrients; 8(11): 733, 2016. doi:10.3390/nu8110733.

7. CHAVES, F.M.; BAPTISTA, I.L.; SIMABUCO, F.M. et al. High-intensity-exercise-induced intestinal damage is protected by fermented milk supplemented with whey protein, probiotic and pomegranate (Punica granatum L.). Br J Nutr; 119: 896-909, 2018.

8. SHING, C.M.; PEAKE, J.M.; LIM, C.L.; et al. Effects of probiotics supplementation on gastrointestinal permeability, inflammation and exercise performance in the heat. Eur J Appl Physiol; 114(1):93-103, 2014.

9. COQUEIRO, A.Y.; OLIVEIRA GARCIA, A.B.; ROGERO, M.M.; TIRAPEGUI, J.Probiotic supplementation in sports and physical exercise: Does it present any ergogenic effect? Nutr Health; 23(4):239-249, 2017.

10. AGUILAR-TOALÁ, J.E.; GARCIA-VARELA, R.; GARCIA, H.S. et al. Postbiotics: An evolving term within the functional foods field. Trends in Food Science \& Technology; 75: 105-114, 2018.

11. MURPHY, L.Y. et al. Influence of functional food components on gut health. Crit Rev Food Sci Nutr; 2018. DOI: 10.1080/10408398.2018.1433629.

12. SUEZ, J.; ELINAV, E. The path towards microbiome-based metabolite treatment. Nature Microbiology; 2: 17075,2017 